\title{
WILL THE GLOBAL ECONOMY USE THE OPPORTUNITY FOR REFORMS, AND THE WORLD FOR PEACE AND COOPERATION?
}

\author{
Petar Đukić \\ Editor-in-Chief of Economics, Journal for Innovation and Economic Research
}

\section{Editorial}

In the Editorial for issue 8 of Economics, wondering where the world of today is going, we noted that all key short-term challenges are on the rise: terrorism, extremism, isolationism... Unfortunately, half a year later, and right before year 2018, we cannot say that things in this respect have become any more favourable. The key word of the majority of analyses of the global economic situation remains to be "risk". Only the list and the meaning of the risk are expanded.

\section{THE WORLD IN TURMOIL - RISKS ON THE RISE}

In mid-November 2017, tens of thousands of well-organized extreme right-wingers marched in the streets of Warsaw (Poland), with slogans about "pure white Poland", as well as about the "alliance of fraternal European nations". Few people could, with certainty presume what it would really mean in practice today, but one thing is certain - nothing good for global economic and other types of cooperation as well as for the principle of tolerance. Many emerging extremist political options came into foreground through recent elections across Europe, from the Netherlands, to Germany and France. The share of extremist parties in the electorate body at the end of the 20th century amounted to between 4 and 5\%, whereas today it is around 14\%. Enclosure, isolationism and calling for "a firm hand" are part of a "strategy" of seeking a surreal solution to the challenges that come in continuity.

Simply put, terrorism has made itself at home throughout the World. When, in the attack on the Sinai Mosque (24 November 2017) 305 people, including 17 children, instantly lost their lives, it is as if such event no longer leaves the impression of anxiety and disgust as it was the situation with large European centres, (Paris, two years earlier), not even to mention 11 September 2001 in the United States. An extraordinary and a very positive gesture of inter-religious solidarity is the appeal of Pope Francis (26 November 2017) to Catholic believers gathered in the Vatican Square to pray for the Muslim believers who were killed in their prayer.

However, the question is whether the politically organized world, at its highest level, is becoming insensitive to the suffering of "others", as well as for the global problems, such as "sabre rattling", isolationism, the burden of refugee waves, and even including certain aspects of climate change? How to encourage global solidarity and cooperation that are missing in today's world more than ever before? Does this have anything to do with the principles of the ruling global economic system? 


\section{GROWTH AND DEVELOPMENT AS A CHANCE AND RISK}

The growth rate of global gross domestic product in 2017, according to IMF reports, should be $3.6 \%$ instead of $3.5 \%$ with the prospect that in the next year 2018, such rate should rise to $6.7 \%$. However, previous corrections, were, as a rule, made "downwards" so that, from the perspective of 2012, the current growth should have been as much as $4.5 \%$ per year. Long-term sustainable growth rates of global economic activity are some kind of guarantee of stability and cooperation in the divided world. In its October report, the IMF notes that After disappointing global growth over the past few years, this recent pickup provides an ideal window of opportunity for policymakers to undertake critical reforms to stave off downside risks, raise potential output, and improve living standards more broadly (World Economic Outlook, October 2017). The subtitle of the Report states that short-term recovery is at work, but that the need for a long-term and sustainable growth remains. It seems that in this discourse, which is oriented towards the benefits of broader layers of society, the key syntagm for overcoming the crisis should be sought. It is a "general well-being", which stems from the principle of as many beneficiaries of the effects of global growth and development.

Somehow, on the completely opposite side of the value scale is the category "risk". It is derived out of uncertainty, and by nature it represents the possibility or probability of a bad outcome. However, the risks by themselves often cause unreasonable consequences. Sometimes, they are even considered as desirable, as in the case of free entrepreneurship - for example. The market, like any other principle of free choice, contains a dose of risk.

However, things become more complicated by the fact that the risk in today's world is increasing. Sustainability, as the most mentioned target category of today's integral and global development contains the security principle - as a lack of risk. How to create a safer society, co-operation in peace, more effective and stable economy, better-quality culture, protected environment, with as little risk and as much freedom as possible? The life itself will continue to provide incomplete and often contradictory answers to these questions. This does not mean that better institutional solutions on the same issues should not be sought.

\section{EXTREMISM - ITS FOUNDATION IN THE ECONOMY AND THE SOCIAL SYSTEM}

For something to represent a risk it first must be recognized as a threat, a factor that contributes to an unfavourable outcome. Unemployment and social stagnation seem to lead more and more helpless people against one another. This time, antagonism is felt towards the people of a different skin colour, religion or towards people with different customs. They are most frequently helpless but cause suspicion and even fear, but not only because they are different. There seems to be a much greater problem in the same or similar aspirations towards a better place to live, more resources, better jobs, salaries, welfare... Certain people, the insecure and worried ones, intimidated by the escalation of global geopolitical and other contradictions, tend to invest more trust in national liberators, extremists and populists of a new anti-globalist and isolationist orientation. After all, if Donald Tramp, right after the elections, issued an order to build a 4 metres high and a thousand miles long wall between the United States and Mexico, how could such "projects" be avoided by Hungary, Turkey or any other smaller country with higher risks?

In today's world, there are officially over 200 million unemployed, whereas over $60 \%$ of all the workers perform their work without any work contract. Most of them are engaged in family business in developing countries. Simultaneously, among those who do have a job, far less than a half of them (42\%) have a permanent employment contract (World Employment and Social Outlook: Trends 2017). What is particularly worrying is the situation in low-income countries, due to the increasing problems of inequality and falling behind in terms of the benefits of global 
growth. It was shown that the so-called. part time jobs and other flexible forms of employment can foster better function of labour market and economic growth, but they often bring new issues. Working conditions and the amount of real wages are worsening. Therefore, for example, nominal wage growth in most advanced economies remains lower than it was prior to the major recession of 2008-2009. The poor situation in the labour market is spurred by low inflationary expectations as well as by labour productivity trends. Poor real wages reduce the prospects for growth in the medium term, even in developed economies, although the critical challenges of accepting the new economy still remain in low income countries.

As a result, it seems that the economic stability itself does not help directly to increase employment, and especially not to reduce social tensions, as well as global differences and contradictions. Natural, financial, and human resources in the World are not distributed in such manner so that ones are constantly living in abundance whereby the others are constantly lacking something, but it can easily look like that very often. This is just one extreme in searching for the answer of one's failure to succeed and why the tide does not "raise all vessels" equally, as the international financial institutions, in particular the World Bank, believed.

\section{CLIMATE AS AN “ECONOMIC” FACTOR}

The famous astrophysicist Stephen Hawking recently provided another "apocalyptic prognosis about the world we live in". He declared that the Planet would become a "glowing fireball" in less than 600 years. He also said that people would have to "boldly go where no one has gone before", if they want humanity to survive. The Earth will be overcrowded by the year 2600, whereas the increased energy consumption will turn Earth into a "bright fireball." This implies a multitude of new findings not previously taken into serious consideration. Nowadays, people think much differently about geophysical changes, the environment, basic natural resources (water, air, available space and soil, ecosystems...) as the preconditions of every sustainable economy and society. It is therefore probably meaningless to split the factors that determine the short- or long-term future into economic and non-economic ones.

For the first time in the analysis of movements of the world economy in the October report and IMF analysis, it was stated that the global temperature is unprecedently rising perceived through the last 40 years, and that it will have strong and unexpected macroeconomic effects. Particularly endangered are the countries with a relatively warm climate and low income. Regardless on how much the causes of climate change were the subject of disputes, in terms of domination of the anthropogenic or natural factors to their occurrence, it should have already been made clear to economists and other social analysts and institutions that climate, water, temperature, sunshine, greenhouse gas emission ... cannot be separated from other negative factors that endanger the life and survival of people.

\section{DEGLOBALISATION AND SOCIAL RISKS}

The connection of deglobalisation in advanced economies and rising social risk is a subject of warning provided by the World Economic Forum (WEF) that has been researching the list of key global risks for a decade. It is noted that the key risks for 2011 are focused on the economic differences and global failures of governments, in 2014 on the social consequences of a possible collapse of the social structure, then on the collapse of trust in the institutions, lack of quality leadership, gender inequality and treatment of women, weaknesses of the leaders and the steady rise of inequalities throughout the world, in 2015 on the vulnerability due to growing social 
contradictions, etc. History shows that people reflect their own sense of impotence and control over the general flows of geopolitics, economics and social problems onto the sense of and the recognition of risks that threaten from the global scene.

In 2016, additional events in the West, such as Britain's exit from EU, election of Donald Trump as the President of the United States, Italian Electorate's rejection of Matteo Renzi's constitutional reforms demonstrate that the era of deglobalisation has started in the West. Most certainly, social structural changes are linked to the above thus reducing the share of the middle class in the world. For a decade, the World Economic Forum has been trying to assess the sequence of global risks, which include natural, socio-economic, geopolitical, environmental, technological ... Many of them overlap and are defined year after year. For example, the most prominent risk in the long term for 2016 was water supply, whereas in 2017, economic risks are again among the highest ones: unemployment and insufficient employment, but also including the spread of weapons of mass destruction.

The key challenges in the world whose resolution would lead to risk reduction are as follows:

1. Achieving greater solidarity and long-term thinking about market capitalism

2. Restoration of quality global economic growth

3. Identification of the importance of identity and inclusiveness of the health policy

4. Mitigating technological risks and exploiting the opportunities provided by the 4 th technological revolution

5. Strengthening of today's global cooperation system

\section{FUTURE WORLD - MONDIALISM OR DEGLOBALISATION}

Today's research of the World Economic Forum shows that, based on global changes in world public opinion, developed western countries are nowadays mostly saturated with globalisation, and that extreme and conservative (anti-globalist) political options are much more present in the West than in the early 21st century. However, despite the fact that many phenomena of globalisation are being questioned and attributed to a multitude of old changes and ancient civilizations, it is being shown that it is inseparable from modernization (technological progress), but also from the stoic philosophy and the so-called "citizen of the world" attitude. Multiculturalism, cultural diversity cultural diversity are mentioned as the positive effect of globalisation. Namely, it has been established that cultural interactions and cultural exchange and tolerance bring benefits to the community, society and cities. On the other hand, the social policy that promotes multiculturalism is frequently blocked by the practice of excluding minority groups from the wider cultural and social space, which turns into a tendency towards fragmentation and new divisions, already established in political theory as balkanization.

Conservatism is a feeling fuelled by the arguments of tradition, historical interest, friendship and hostility, with almost equal zeal, as it was at the time of the breakup of Yugoslavia. The analysis of domestic assumptions suggests that such conservative patterns are today far more present in Europe, as well as throughout the Balkans, than it was the case at the beginning of the 21 st century, and that they are growing in power with the deepening of the economic crisis and the sharpening of global geopolitical contradictions.

The crisis of globalisation, as a value, is felt largely in the twilight of this term and practice in a number of developed countries in Europe and in the United States, particularly after the UK's decision to leave the EU, the election of Donald Tramp as the US President and after the recent referendum in which the Catalans were mostly for secession from the rest of Spain. Reports on global risk movements (regular annual assessment of the World Economic Forum - WEF), based on the 2017 Report, show that situation is fairly complicated by the strengthening of extreme 
and populist options throughout the world. Economist Dani Rodrick, coined the syntagm "the globalisation trilemma" that implies a settlement or equilibrium "among democracy, national sovereignty and global economic integration." He believes that only the first two categories are simultaneously compatible today, as the EU and the US increasingly express their will to rebalance the relationship between national sovereignty and democracy" (Global risks 2017. (http://reports. weforum.org/global-risks-2017/part-1-global-risks-2017/?doing_wp_cron=1510405069.5533540 248870849609375).

This euphemistic expression speaks enough about the crisis of the concept of global cooperation based on democratic principles. Likewise, in the Balkan region, which has long been named as "barrel of gunpowder", there is a multitude of signals for change, either as obstacles, closures and divisions (balkanization) but as a challenge as well. The increase in risk in the world in a certain way explains that balkanization (the principle of endless divisions and insisting on differences) is occasionally transmitted to the rest of the world, instead of opposite action - to have the positive rules of co-operative behaviour and cooperation extend everywhere, including the Balkans.

Based on the 10-year ranking of globally-valued risks in terms of the likelihood of their occurrence, it is notable that the first five are essentially repeated, but that their order tends to change. According to WEF, these risks can be divided into five categories:

ecological - total 10 - from year to year, trend of increase;

economical - total 5 - with a permanent maintenance trend, average one of the top five; geopolitical - total 5;

social - total 5 - with a trend of increase following 2015;

technological - total 2.

It is definitely that an increasing number of risks is becoming more and more worrying on a global scale. Today, new and old risks are endangering people's lives and quality much more than before. It is a trend that will not change soon, bearing in mind that the general living and ecological capacity of the Earth is severely contradicted by the trends of population growth, economic activity and people's demand for material goods, energy and services.

More than ever before it is necessary to have "good governance" as a method to establish good relations in a society that Galbraith once called "good society". He has convincingly demonstrated that social inclusion (inclusion of marginal groups and individuals in the social life), social justice, environmental protection, taxation and income policy, attitude towards women and minorities, may create a good society from the economic and socio-political system. In a good society, as stated by Galbraith, the risks of deviant behaviour, crime, social conflicts are reduced, whereas the society itself continually achieves results in internal and external politics, so that it manages to cut spending on national defence, security and military interventions, and to increase spending for humanitarian, environmental and socially justified goals. "(The Good Society: The Humane Agenda, Paperback - April 30, 1997)

Market economy implies greater and increasingly more risks in comparison to planning or command economy, but it provides much more freedom and a greater chance of development. The application of the law, together with the social security system, should mitigate the effects of globalisation, competition, privatisation and restructuring of the public sector of the economy. These issues were often too sensitive to be left to the mercy of the current structure in power. They demanded a far more strategic analytical approach derived from the category of integral sustainability and risk minimization. Today's dilemma; mondialism or deglobalisation is completely obsolete. The world needs international peace-keeping economic and technological cooperation more than ever. Deglobalisation is a poor answer to the wrong question. Instead, it is much better to search for patterns of a socially and environmentally responsible, inclusive market solution.

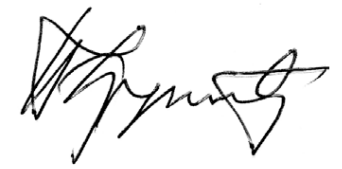

